Reinhold Merkelbach

Die Hirten des Dionysos 



\section{Reinhold Merkelbach}

\section{Die Hirten des Dionysos}

Die Dionysos-Mysterien der römischen Kaiserzeit und der bukolische Roman des Longus

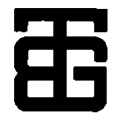

B. G. Teubner Stuttgart 1988 
Gedruckt mit Unterstützung der Förderungsund Beihilfefonds Wissenschaft der VG WORT GmbH, Goethestraße 49, 8000 München 2

CIP-Titelaufnahme der Deutschen Bibliothek

Merkelbach, Reinhold:

Die Hirten des Dionysos : d. Dionysos-Mysterien d. röm.

Kaiserzeit u.d. bukol. Roman d. Longus / Reinhold

Merkelbach. - Stuttgart : Teubner, 1988

ISBN 3-519-07410-9

Das Werk einschließlich aller seiner Teile ist urheberrechtlich geschützt. Jede Verwertung außerhalb der engen Grenzen des Urheberrechtsgesetzes ist ohne Zustimmung des Verlages unzulässig und strafbar. Das gilt besonders für Vervielfältigungen, Übersetzungen, Mikroverfilmungen und die Einspeicherung und Verarbeitung in elektronischen Systemen.

(C) B. G. Teubner Stuttgart 1988

Printed in Germany

Gesamtherstellung: Passavia Druckerei GmbH Passau 